\title{
A High Efficiency Si-Ge Based Novel Multijunction Solar Cell
}

\author{
J. Sultana ${ }^{1}$, M. A. Habib ${ }^{1 *}$, S. N. Sakib ${ }^{2}$, M. S. Mina ${ }^{1}$ \\ ${ }^{1}$ Physics Discipline, Khulna University, Khulna-9208, Bangladesh \\ ${ }^{2}$ Department of ETE, Daffodil International University, Dhaka-1207, Bangladesh
}

\begin{abstract}
This research is focused on a new type of three junction high efficiency solar cell incorporating the promising Si-Ge material as the bottom layer. As a proof of concept, the proposed solar cell has been configured with high quality material of bandgaps $1.9 \mathrm{eV}$ $\mathrm{GaInP}_{2}$ and $1.42 \mathrm{eV} \mathrm{GaAs}$ as top and middle subcells and $0.838 \mathrm{eV}$ bandgap $\mathrm{Si}_{0.38} \mathrm{Ge}_{0.62}$ new semiconductor material as bottom subcell. The chosen materials for this configuration are lattice matched (5.66 A) and this matching is beneficial for optical transparency and current conductivity. The short circuit current density $\left(J_{s c}\right)$, reverse saturation current density $\left(J_{0}\right)$, open circuit voltage $\left(V_{o c}\right)$, voltage $\left(V_{m}\right)$ and current density $\left(J_{m}\right)$ at maximum power point, fill factor $(F F)$ and the photoconversion efficiency

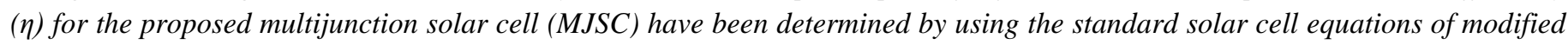
spectral p-n junction model and MATLAB in-house code. The ASTM G173-03 reference spectra have been utilized for the quantitative analysis at airmass $A M 1.5 \mathrm{G}$ global irradiance condition. The conversion efficiency of the $\mathrm{GaInP} \mathrm{P}_{2} / \mathrm{GaAs}_{s} / \mathrm{Si}_{0.38} \mathrm{Ge}_{0.62}$ solar cell has been simulated as $47.1 \%$ at AM1.5G under normal sun (1 sun) concentration and $56.4 \%$ under 1000 suns concentration.
\end{abstract}

Keywords: Multijunction, Solar cell, Si-Ge, Simulation, Conversion efficiency.

\section{INTRODUCTION}

Fossil fuels had been the reliable sources of energy since the advent of human civilization [1]. Its detrimental effect on the environment was ignored earlier due to some obvious reasons but not anymore. With the increasing use of fossil fuels over the years, the world has experienced its adverse effect- the climate change. Due to the gradual advancement of technology, energy demand is increasing all over the world. Hence scientists are looking for newer energy sources to meet the regular need for the gradually increasing population. On the other hand, the global warming issue due to extra carbon emission and deforestation has diverted scientists to search for renewable energy sources. Thus, power generation by utilizing photovoltaic effect has become a promising tool to mitigate the challenge. Since fossil fuels and other non-renewable energy sources are limited and will be diminished with time, researchers are working for successful harvesting of solar radiation by utilizing photovoltaic (PV) technologies. The first true p-n junction based single silicon solar cell was reported in $1954[2,3]$ and to date, this type of solar cells are the PV market dominant [2]. But their performance is obstructed by the limited efficiencies for covering a short band of the solar spectrum and more manufacturing cost as compared to the electricity from the conventional fossil fuels. By capturing the whole spectrum of the solar radiation, the device can be more efficient. Only one of the options to capture photons from the wider range of solar spectrum is to manufacture devices comprising a number of $\mathrm{p}-\mathrm{n}$ junctions of different band gaps called multijunction solar cells (MJSCs) [4].

MJSCs, mainly used for space applications, are constructed by assembling solar cells of various band gaps on top of each other. The sequence of this combination is such that the band gap of a material decreases from the top to the bottom of the stack for minimizing the heat loss as well as inefficient energy conversion in the upper cells [5]. Typical growths of MJSCs are performed on Ge substrates but due to its comparatively lower bandgap $(0.67 \mathrm{eV})$, mobility and carrier concentrations, $\mathrm{Ge}$ is capable of generating very small amount of open circuit voltage, thus leads to generate a comparatively lower conversion efficiency [6]. For this reason, different research groups are trying to replace Ge from the bottom cell. Hence, Si-Ge based MJSC can be a good choice for new solar cell configuration. Silicon has a moderate band gap of $1.1 \mathrm{eV}$ with a cut off wavelength $1200 \mathrm{~nm}$ and as $\mathrm{Si}$ has a good radiation resistance, the combination of Ge with Si as a bottom layer for an MJSC is supposed to increase the band gap value to cover a wider range of photons wavelength [7, 8]. In this work, the photoconversion efficiency of $\mathrm{GaInP}_{2} / \mathrm{GaAs} / \mathrm{Si}_{0.38} \mathrm{Ge}_{0.62}$ MJSC has been simulated for normal and concentrating sun conditions using indigenously written MATLAB code (MathWorks 2017). To the best of our knowledge, there is no such type of work performed using any simulators in photovoltaic literature specifically for $\mathrm{GaInP}_{2} / \mathrm{GaAs} / \mathrm{Si}_{0.38} \mathrm{Ge}_{0.62}$ solar cell. 
International Journal of Advances in Scientific Research and Engineering (ijasre), Vol 7 (3), March -2021

\section{MATERIALS AND METHODS}

\section{2a. Materials}

The MJSCs can be configured in a range of materials having different bandgaps. Since all the incident photons are not absorbed in the top layer, so it needs to traverse through the middle and bottom layers to be captured. Transparency of the layers is another important issue for material selection. Anti-reflection layer also plays a vital role by obstructing reflection of the solar radiation from the surface of the layer to reduce loss. MJSCs could be stacked either in lattice matched condition or inverted metamorphic (IMM) or lattice mismatched configurations [9]. However, different layers having a range of band gaps of the MJSC also need to be lattice matched to overcome loss due to strain-induced defects. In this work, all of three semiconductor III-V materials $\mathrm{GaInP}{ }_{2}$, GaAs and $\mathrm{Si}_{0.38} \mathrm{Ge}_{0.62}$ have been configured in lattice matched condition as presented in Fig. 1 .

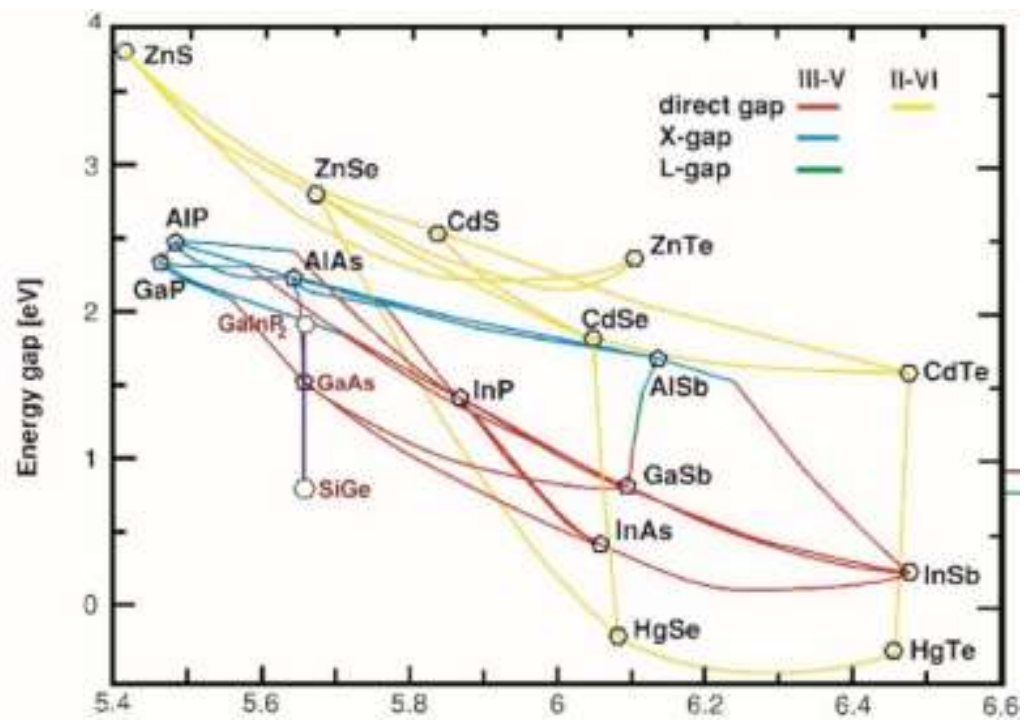

Figure 1: Bandgap of $\mathrm{GaInP}_{2}, \mathrm{GaAs}$ and $\mathrm{Si}$-Ge with their lattice constant $\left(\sim 5.66^{0}\right)$ at $300 \mathrm{~K}$ adopted with reference [10]

Figure 1 presents that MJSC needs strict and certain material choice, because every compound semiconductor material has a certain bandgap and lattice constant. These quantities mainly depend on the lattice match, bandgap match and other optical and electrical properties. The proposed configuration of $\mathrm{GaInP}_{2} / \mathrm{GaAs} / \mathrm{Si}_{0.38} \mathrm{Ge}_{0.62}$ solar cell has been demonstrated in Fig. 2.

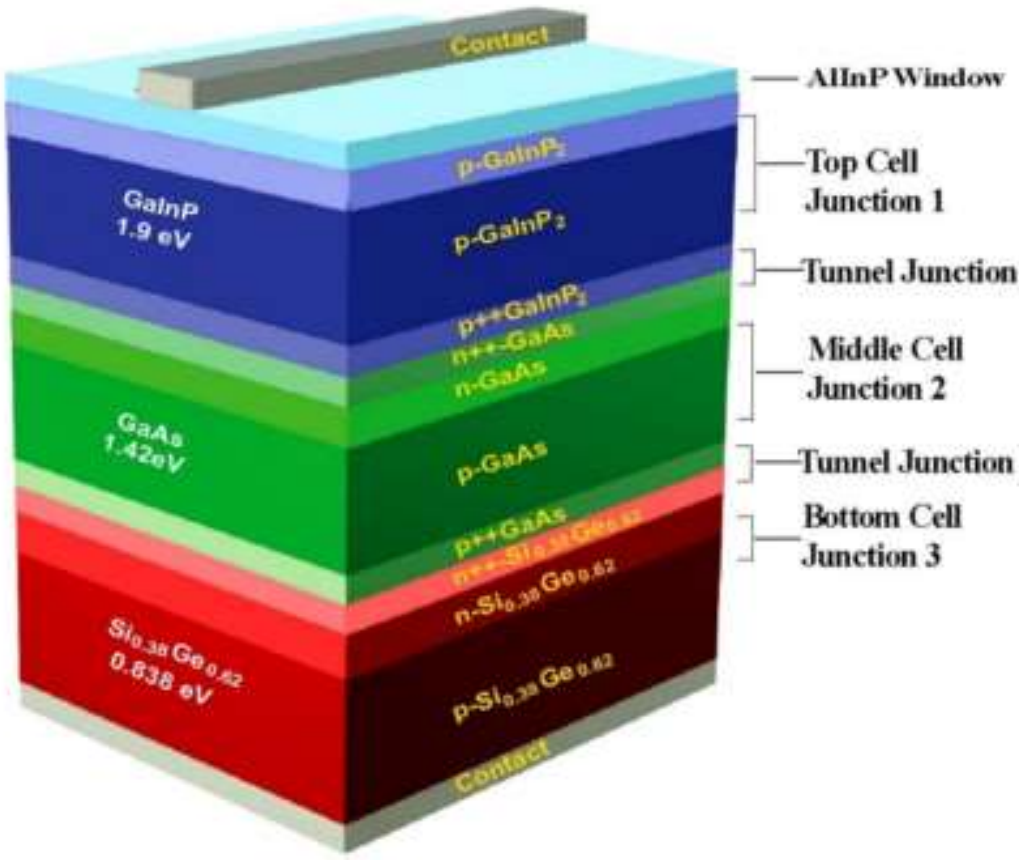

Figure 2: Schematic diagram of proposed $\mathrm{GaInP}_{2}, \mathrm{GaAs}, \mathrm{Si}_{0.38} \mathrm{Ge}_{0.68}$ solar cell 
International Journal of Advances in Scientific Research and Engineering (ijasre), Vol 7 (3), March -2021

\section{2b. Methods}

In this work, the simulations have been performed using a modified spectral p-n junction model [11-13]. According to this model, the short-circuit current density $\left(\mathrm{J}_{\mathrm{sc}}\right)$ has been calculated from the ASTM G 173-03 reference spectrum [14]. By using the irradiance data, the $\mathbf{J}_{\mathrm{sc}}$ has been calculated using the equation as [11]:

$$
J_{S C}=e \times F
$$

Where, $e=$ charge of an electron and photon flux, $F=C \lambda I / h c$. Here, $\lambda=$ wavelength, $I=$ irradiance, $h=$ Planck's constant, $c=$ speed of light, $C=$ sun concentration and for 1 sun concentration, $C=1$.

The reverse saturation current density, $J_{0}$ can be expressed as $[12,13]$,

$J_{0}=e\left(\frac{D_{e}}{\tau_{e}}\right)^{\frac{1}{2}} \frac{n_{i}^{2}}{N_{A}}\left(\frac{S_{e}\left(\frac{\tau_{e}}{D_{e}}\right)^{\frac{1}{2}} \cosh \left(\frac{x_{p}}{\sqrt{D_{e \tau_{e}}}}\right)+\sinh \left(\frac{x_{p}}{\sqrt{D_{e \tau_{e}}}}\right)}{S_{e}\left(\frac{\tau_{e}}{D_{e}}\right)^{\frac{1}{2}} \sinh \left(\frac{x_{p}}{\sqrt{D_{e \tau_{e}}}}\right)+\cosh \left(\frac{x_{p}}{\sqrt{D_{e \tau_{e}}}}\right)}\right)+e\left(\frac{D_{h}}{\tau_{h}}\right)^{\frac{1}{2}} \frac{n_{i}^{2}}{N_{D}}\left(\frac{S_{h}\left(\frac{\tau_{h}}{D_{h}}\right)^{\frac{1}{2}} \cosh \left(\frac{x_{n}}{\sqrt{D_{h} \tau_{h}}}\right)+\sinh \left(\frac{x_{n}}{\sqrt{D_{h} \tau_{h}}}\right)}{S_{h}\left(\frac{\tau_{h}}{D_{h}}\right)^{\frac{1}{2}} \sinh \left(\frac{x_{n}}{\sqrt{D_{h} \tau_{h}}}\right)+\cosh \left(\frac{x_{n}}{\sqrt{D_{h} \tau_{h}}}\right)}\right)$

Here,

$D_{e}$ and $D_{h}$ represent the diffusion current constants for electron and hole, $N_{A}$ and $N_{D}$ are the acceptor and donor concentrations, $S_{e}$ and $S_{h}$ are the Surface recombination velocities for electron and hole, $N_{i}$ is the intrinsic carrier concentration, $\tau_{e}$ and $\tau_{h}$ are the minority carrier lifetime for electron and hole and, $x_{p}$ and $x_{n}$ are the thickness of p-layer and n-layer.

The above equation can be simplified as, $J_{0}=e S_{e} \frac{n_{i}^{2}}{N_{A}}+e S_{h} \frac{n_{i}^{2}}{N_{D}}$

From the Einstein's relationship, $D_{e}=k T \mu_{e} / e$ and $D_{h}=k T \mu_{h} / e$, Where, $k=$ Boltzmann's constant

The minority carrier life time, $\tau_{e}=\frac{1}{\frac{1}{\tau_{S R H}}+B N_{A}}$ and $\tau_{h}=\frac{1}{\frac{1}{\tau_{S R H}}+B N_{D}}$

Where, $B=$ Direct band-band recombination coefficient and $\tau_{S R H}=$ Shockley-Read-Hall life time.

The surface recombination velocities are: $S_{e}=\left(\frac{D_{e}}{\tau_{e}}\right)^{1 / 2}$ and $S_{h}=\left(\frac{D_{h}}{\tau_{h}}\right)^{1 / 2}$

The intrinsic carrier concentration: $n_{i}^{2}=4 M_{c} M_{v}\left(\frac{2 \pi k T}{h^{2}}\right)^{3}\left(m_{e}^{*} m_{h}^{*}\right)^{3 / 2} e^{-\frac{E g}{k T}}$

$$
n_{i}^{2}=N_{c} N_{v} e^{-\frac{E g}{k T}}
$$

Where, $M_{c}=$ No. of equivalent minima in the conduction band, $M_{v}=$ No. of equivalent minima in the conduction band, $N_{c}=$ Effective density of states (DOS) at conduction band (CB) edge, $N_{v}=$ Effective DOS at valence band (VB) edge, $E_{g}=h c / \lambda$, Energy gap of the material, $m_{e}^{*}=$ Effective mass of electrons, $m_{h}^{*}=$ Effective mass of holes, and $\mathrm{T}=$ Temperature

\section{POSTULATION AND PARAMETERS}

The optoelectronic parameters of different materials used for the three layers are collected from the references [12, 15-17] at $300 \mathrm{~K}$. The input power density for air mass $1.5 \mathrm{G}$ is $1000 \mathrm{~W} / \mathrm{m}^{2}[13]$.

Table 1: Optoelectronic parameters for the proposed MJSC

\begin{tabular}{|l|c|c|c|}
\hline \multicolumn{1}{|c|}{ Parameter } & GaInP & GaAs $_{2}$ & $\mathbf{S i}_{\mathbf{0 . 3 8}} \mathbf{G e}_{\mathbf{0 . 6 2}}$ \\
\hline Band gap $\left(\boldsymbol{E}_{\boldsymbol{g}}\right)$ & $1.9 \mathrm{eV}$ & $1.42 \mathrm{eV}$ & $0.838 \mathrm{eV}$ \\
\hline Wavelength $(\boldsymbol{\lambda})$ & $0.65428 \times 10^{-6} \mathrm{~m}$ & $0.875 \times 10^{-6} \mathrm{~m}$ & $1.483 \times 10^{-6} \mathrm{~m}$ \\
\hline Electron Mobility $\left(\boldsymbol{\mu}_{\boldsymbol{e}}\right)$ & $0.4 \mathrm{~m}^{2} /(\mathrm{Vs})$ & $0.2322 \mathrm{~m}^{2} /(\mathrm{Vs})$ & $0.6916 \mathrm{~m}^{2} /(\mathrm{Vs})$ \\
\hline Hole mobility $\left(\boldsymbol{\mu}_{\boldsymbol{h}}\right)$ & $0.02 \mathrm{~m}^{2} /(V s)$ & $0.02 \mathrm{~m}^{2} /(\mathrm{Vs})$ & $0.107 \mathrm{~m}^{2} /(\mathrm{Vs})$ \\
\hline $\boldsymbol{m}_{\boldsymbol{e}}^{*} / \boldsymbol{m}_{\boldsymbol{e}}$ & 0.155 & 0.067 & 0.19 \\
\hline $\boldsymbol{m}_{\boldsymbol{h}}^{*} / \boldsymbol{m}_{\boldsymbol{h}}$ & 0.460 & 0.473 & 0.172 \\
\hline $\begin{array}{l}\text { Shockley-Read-Hall lifetime } \\
\left(\boldsymbol{\tau}_{\boldsymbol{S R H}}\right)\end{array}$ & $10^{-5} \mathrm{~s}$ & $10^{-5} \mathrm{~s}$ & $10^{-5} \mathrm{~s}$ \\
\hline
\end{tabular}


International Journal of Advances in Scientific Research and Engineering (ijasre), Vol 7 (3), March -2021

\begin{tabular}{|l|c|c|c|}
\hline $\begin{array}{l}\text { Direct band-band } \\
\text { recombination coefficient }(\boldsymbol{B})\end{array}$ & $7.5 \times 10^{-16} \mathrm{~s}^{1} \mathrm{~m}^{3}$ & $7.5 \times 10^{-16} \mathrm{~s}^{1} \mathrm{~m}^{3}$ & $7.5 \times 10^{-16} \mathrm{~s}^{1} \mathrm{~m}^{3}$ \\
\hline Acceptor concentration $\left(\boldsymbol{N}_{\boldsymbol{A}}\right)$ & $1 \times 10^{23} \mathrm{~m}^{-3}$ & $9 \times 10^{23} \mathrm{~m}^{-3}$ & $1 \times 10^{23} \mathrm{~m}^{-3}$ \\
\hline Donor concentration $\left(\boldsymbol{N}_{\boldsymbol{D}}\right)$ & $2 \times 10^{24} \mathrm{~m}^{-3}$ & $7.8 \times 10^{23} \mathrm{~m}^{-3}$ & $2 \times 10^{24} \mathrm{~m}^{-3}$ \\
\hline Lattice constant $(\AA)$ & $5.66 \times 10^{-10} \mathrm{~m}$ & $5.659 \times 10^{-10} \mathrm{~m}$ & $5.59 \times 10^{-10} \mathrm{~m}$ \\
\hline
\end{tabular}

\section{RESULTS AND DISCUSSION}

As the single junction solar cell manufactured from Si has reached approximately its theoretical limit of efficiency [9], more extensive research work has been carried out in the field of multijunction solar cells to obtain higher power conversion efficiency. With the development of growth technologies like Molecular Beam Epitaxy (MBE), Metallorganic Chemical Vapour Deposition (MOCVD), III-V compound semiconductors have attracted researchers to investigate the possibility of using the materials in solar photovoltaic productions. This has necessitated the exploration of new materials for solar photovoltaic applications.

In this work, all subcell materials of the MJSC are lattice-matched with each other and with growth substrates for reducing recombination losses due to the strain-induced defects arising from the lattice parameter mismatch of the juxtaposed semiconducting materials. Strain-induced defects reduce the solar cell performance. This lattice-matched structure can minimize thermalization and non-absorption losses as different band gaps absorb the corresponding solar spectrum. By this way, the MJSC can generate higher photoconversion efficiencies than any conventional single junction solar cells. To date, champion triple junction $\mathrm{GaInP} / \mathrm{GaAs} / \mathrm{InGaAs}$ is able to exceed $44 \%$ efficiency [9].

Absorption coefficient has a great impact on solar cells and it has been seen that, for greater absorption coefficient more photons are absorbed. In series connected MJSCs, the series resistance affects the Jsc, in fact, reduction of Jsc increases the Voc. Since the top cell thickness would be the adjusting parameter, hence its thinning will enhance the total solar cell efficiency. Sun concentration plays a vital role on solar cell efficiency. However, for simulating the new model solar cell $\mathrm{GaInP} / \mathrm{GaAs} / \mathrm{Si}_{0.38} \mathrm{Ge}_{0.62}$ zero loss from reflection, grid coverage and series resistance were considered. The simulation program was started with the evaluation of the short-circuit current $\left(\mathrm{J}_{\mathrm{sc}}\right)$ and then other parameter such as $\mathrm{J}_{0}, \mathrm{~V}_{\mathrm{oc}}, \mathrm{J}_{\mathrm{m}}, \mathrm{V}_{\mathrm{m}}, \mathrm{FF}$ and $\eta$ were calculated by using the MATLAB in-house coding of the standard solar cell equations mentioned in the model of Section 2. The required optoelectronic parameters were utilized from Table-1. The MATLAB simulated results for $\mathrm{GaInP}_{2} / \mathrm{GaAs} / \mathrm{Si}_{0.38} \mathrm{Ge}_{0.62}$ have been presented in Table-2 for airmass AM1.5G under 1 sun condition.

Table 2: Total cell parameters for proposed configuration

\begin{tabular}{|l|c|}
\hline \multicolumn{1}{|c|}{ Parameters } & Proposed Configuration $\mathbf{G a I n P} \mathbf{P}_{\mathbf{2}} / \mathbf{G a A s}_{\mathbf{S}} / \mathbf{S i}_{\mathbf{0 . 3 8}} \mathbf{G e}_{\mathbf{0 . 6 2}}$ \\
\hline Current Density, $\mathrm{J}_{s c}$ & $177.2723\left(\mathrm{~A} / \mathrm{m}^{2}\right)$ \\
\hline Total open circuit voltage, $\mathrm{V}_{\mathrm{oc}}$ & $2.8038 \mathrm{~V}$ \\
\hline Maximum Voltage, $\mathrm{V}_{\mathrm{m}}$ & $2.6830 \mathrm{~V}$ \\
\hline Maximum Current Density, $\mathrm{J}_{\mathrm{m}}$ & $175.5758\left(\mathrm{~A} / \mathrm{m}^{2}\right)$ \\
\hline Fill factor, FF & 0.9477 \\
\hline Efficiency, $\eta$ & $47.1072 \%$ \\
\hline
\end{tabular}

The current-voltage $\left(\mathrm{J}_{\mathrm{sc}}-\mathrm{V}\right)$ characteristics for the Si-Ge based solar cell has been presented in Fig. 3. The $\mathrm{J}_{\mathrm{sc}}$ differs from the three subcells for absorbing three different solar radiation spectra due to the variation of bandgap energy of the subcell materials. In this simulation work, the bottom subcell generates the lowest $\mathrm{J}_{\mathrm{sc}}$. As the subcells are series connected, the lowest $\mathrm{J}_{\mathrm{sc}}$ determines the total current density of the solar cell. Hence the conversion efficiency of an MJSC depends on the short circuit current density of the bottom layer [4]. 


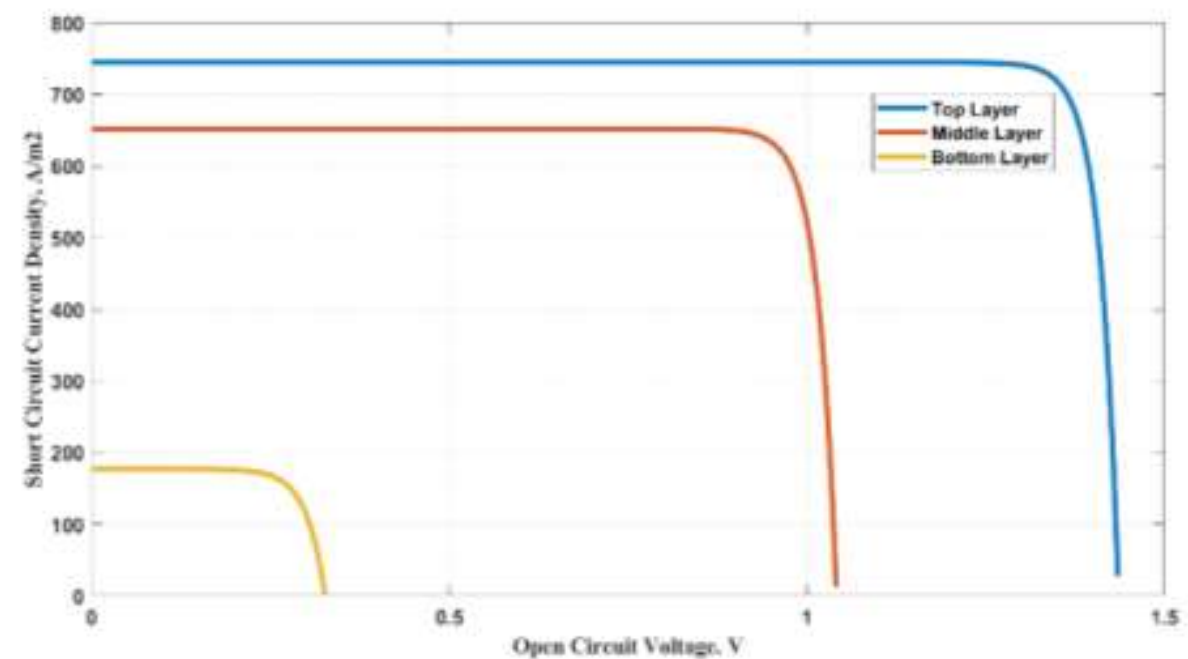

Figure 3. $J_{s c}-V$ characteristics curve for the proposed configuration

In this work, the total current density was simulated as $177.2723 \mathrm{~A} / \mathrm{m}^{2}\left(17.72 \mathrm{~mA} / \mathrm{cm}^{2}\right)$. The $\mathrm{V}_{\mathrm{oc}}, \mathrm{J}_{\mathrm{m}}, \mathrm{V}_{\mathrm{m}}$, FF and $\eta$ were calculated as $2.8 \mathrm{~V}, 17.56 \mathrm{~mA} / \mathrm{cm}^{2}, 2.68 \mathrm{~V}, 0.94$ and $47.1 \%$ respectively. The fill-factor of the MJSC is found to be very high (0.94). Usually, single junction solar cells generate comparatively lower $(\sim 0.5$ to $\sim 0.9 \mathrm{eV})$ open circuit voltage, where the three junction MJSCs generate $\sim 2.5 \mathrm{eV}$ or more [9]. In fact, this very high $\mathrm{V}_{\text {oc }}$ leads to generate a very high fill-factor, thus ultimately increasing the total cell efficiency. Besides, since the utilized modified model has assumed unity electron-hole pair generation from unit incoming photons and zero loss from reflection, grid coverage and series resistance, these assumptions have further increased the performance of the $\mathrm{GaInP}_{2} / \mathrm{GaAs} / \mathrm{Si}_{0.38} \mathrm{Ge}_{0.62}$ thus in turn, enhance the open circuit voltage, fill-factor and efficiency of the MJSC. However, the obtained conversion efficiency of the three junction solar cell shows a good harmony with the maximum theoretical efficiency under identical atmospheric condition, AM1.5G [4, 18, 19].

The bottom subcell material, Si-Ge alloy, consisted of $1.1 \mathrm{eV}$ bandgap Silicon ( $\mathrm{Si}$ ) and $0.67 \mathrm{eV}$ bandgap Germanium (Ge). Si has a low cost, profuse availability and is an established material for solar cells with a direct bandgap [20, 21]. In general, the suitable bandgap values for an standard single solar cell material is between 1.1 and $1.7 \mathrm{eV} \mathrm{[20],} \mathrm{so} \mathrm{incorporation} \mathrm{of} \mathrm{Si} \mathrm{content} \mathrm{with} \mathrm{Ge} \mathrm{is}$ generated $\mathrm{Si}_{0.38} \mathrm{Ge}_{0.62}$ with a bandgap of $0.834 \mathrm{eV}$ by means of band gap engineering. Due to the physical growth process used for HBT, CMOS, BICMOS Si-Ge can obtain a direct bandgap [15]. This has been in practice using the technologies like Low Pressure Chemical Vapour Deposition (LPCVD), MBE and Ultra High Vacum Chemical Vapour Deposition (UHVCVD). These techniques have been utilized to produce $\mathrm{Si}_{1-\mathrm{x}} \mathrm{Ge}_{\mathrm{x}}$ materials for advanced MOS devices. As the growth incorporates strain on the material, it boosts the values of mobility which is important for optical applications. However, the material can be explored using Photoluminescence that makes it more interesting for solar cell manufacturing. The $\mathrm{Si}_{0.38} \mathrm{Ge}_{0.62}$ bottom layer of configuration has increased the bandgap and contracts the lattice parameter to make a suitable lattice-matched condition [7]. However, the $\mathrm{Si}_{0.38} \mathrm{Ge}_{0.62}$ bottom subcell generated a comparatively higher $\mathrm{V}_{\mathrm{oc}}$ than Ge due to the higher bandgap. This additional increment of open circuit voltage leads to an increase in the overall cell efficiency of $\mathrm{GaInP} \mathrm{P}_{2} / \mathrm{GaAs} / \mathrm{Si}_{0.38} \mathrm{Ge}_{0.62}$.

The simulation was performed in concentrating condition also. Fig. 4. shows the variation of efficiency with sun concentration for the proposed MJSC configuration. It is seen from the graph that the change in efficiency is very small at higher sun concentrating condition as compared to lower concentrating condition. The significant increment of the efficiency occurs up to 1000 Sun concentration for the proposed configuration, because of the material's properties [13]. 


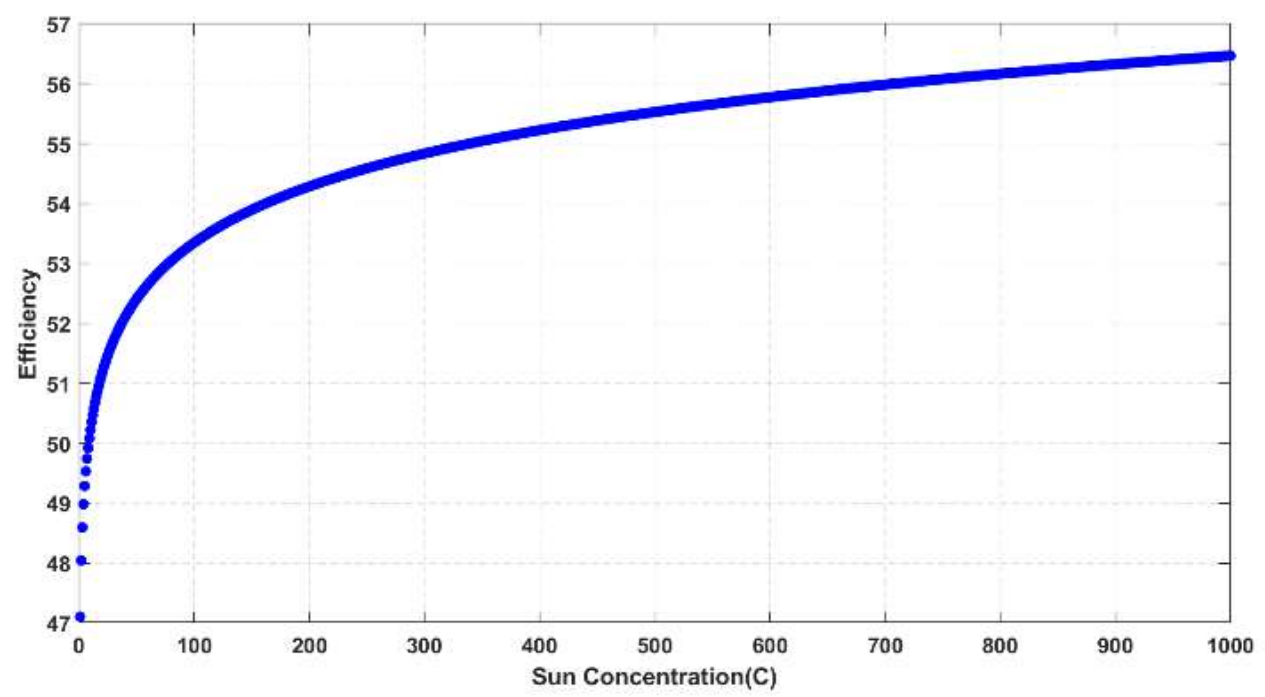

Figure 4: Efficiency vs. Sun concentration response of $\mathrm{GaInP}_{2} / \mathrm{GaAs}_{\mathrm{Si}} \mathrm{Si}_{0.38} \mathrm{Ge}_{0.62} \mathrm{MJSC}$

\section{CONCLUSION}

In this work, the numerical simulation has been performed for new configured multijunction solar cell, $\mathrm{GaInP}_{2} / \mathrm{GaAs} / \mathrm{Si}_{0.38} \mathrm{Ge}_{0.62}$. The photoconversion efficiencies have been obtained as $47.1 \%$ and $56.4 \%$ in normal (1 sun) and concentrating sun (up to 1000 suns) conditions for AM1.5G for the Si-Ge based MJSC using the indigenously written MATLAB code. These simulation results would be helpful for high efficiency MJSC fabrication by using an optical concentrator.

\section{ACKNOWLEDGEMENTS}

This research project was financially supported by Khulna University Research Cell (Ref. No. KURC-04/2000-34) Khulna University, Khulna-9208, Bangladesh. The authors of this paper would like to thank Physics Discipline, Khulna University and, Mr. Saidul Islam and Mr. Sumon Chandra Debnath, Senior Scientific Officers, Institute of Fuel Research and Development (IFRD), Bangladesh Council of Scientific and Industrial Research (BCSIR), Dhaka-1205 for providing technical support and assistance to complete this work successfully.

\section{REFERENCES}

[1] N. Armaroli and V. Balzani, "The legacy of fossil fuels," Chemistry-An Asian Journal, vol. 6, pp. 768-784, 2011

[2] A. Kowsar, S. F. U. Farhad, M. Rahaman, M. S. Islam, A. Y. Imam, S. C. Debnath, "Progress in major thin-film solar cells: Growth technologies, layer materials and efficiencies," International Journal of Renewable Energy Research (IJRER), vol. 9, pp. 579-597, 2019

[3] D. M. Chapin, C. Fuller, and G. Pearson, "A new silicon p-n junction photocell for converting solar radiation into electrical power," Journal of Applied Physics, vol. 25, pp. 676-677, 1954

[4] M. A. Green, "Third generation photovoltaics," P-61, 2006

[5] S. Kurtz, D. Myers, W. McMahon, J. Geisz, and M. Steiner, "A comparison of theoretical efficiencies of multi-junction concentrator solar cells," Progress in Photovoltaics: research and applications, vol. 16, pp. 537-546, 2008

[6] A. Kowsar, K. R. Mehzabeen, M. S. Islam, and Z. Mahmood, "Determination of the theoretical efficiency of GaInP/GaAs/GaAs1-xBix multijunction solar cell," in Proc. of the 10th International conf. on fiber optics and Photonics Photonics, India, 2010

[7] R. Roucka, A. Clark, and B. Landini, "Si-Ge-Sn alloys with $1.0 \mathrm{eV}$ gap for CPV multijunction solar cells," in AIP Conference Proceedings, 2015, p. 040008

[8] J. Geisz, J. Olson, D. Friedman, K. Jones, R. Reedy, and M. Romero, "Lattice-matched GaNPAs-on-silicon tandem solar cells," in Conference Record of the Thirty-first IEEE Photovoltaic Specialists Conference, 2005, pp. 695-698

[9] M. Green, E. Dunlop, J. Hohl-Ebinger, M. Yoshita, N. Kopidakis, and X. Hao, "Solar cell efficiency tables (version 57)," Progress in Photovoltaics: Research and Applications, vol. 29, pp. 3-15, 2021 
International Journal of Advances in Scientific Research and Engineering (ijasre), Vol 7 (3), March -2021

[10] A. Bett, F. Dimroth, G. Stollwerck, and O. Sulima, "III-V compounds for solar cell applications," Applied Physics A, vol. 69, pp. 119-129, 1999

[11] M. E. Nell and A. M. Barnett, "The spectral pn junction model for tandem solar-cell design," IEEE Transactions on Electron Devices, vol. 34, pp. 257-266, 1987

[12] S. R. Kurtz, P. Faine, and J. Olson, "Modeling of two-junction, series-connected tandem solar cells using top-cell thickness as an adjustable parameter," Journal of Applied Physics, vol. 68, pp. 1890-1895, 1990

[13] A. Kowsar and S. F. U. Farhad, "High Efficiency Four Junction III-V Bismide Concentrator Solar Cell: Design, Theory, and Simulation," International Journal of Renewable Energy Research (IJRER), vol. 8, pp. 1762-1769, 2018

[14] A. Standard, "Standard tables for reference solar spectral irradiances: direct normal and hemispherical on $37^{\circ}$ tilted surface," American Society for Testing Materials: West Conshocken PA, USA, 2007

[15] Y. M. Haddara, P. Ashburn, and D. M. Bagnall, "Silicon-germanium: properties, growth and applications," in Springer handbook of electronic and photonic materials, ed: Springer, 2017, pp. 1-1

[16] V. Semiconductor, "The general properties of si, ge, sige, sio2 and si3n4," vol, vol. 10, p. 2012, 2002

[17] S. M. Sze and K. K. Ng, Physics of semiconductor devices: John wiley \& sons, 2006

[18] A. Marti and G. L. Araújo, "Limiting efficiencies for photovoltaic energy conversion in multigap systems," Solar Energy Materials and Solar Cells, vol. 43, pp. 203-222, 1996

[19] A. S. Brown, M. A. Green, and R. P. Corkish, "Limiting efficiency for a multi-band solar cell containing three and four bands," Physica E: Low-dimensional Systems and Nanostructures, vol. 14, pp. 121-125, 2002

[20] A. Goetzberger, J. Luther, and G. Willeke, "Solar cells: past, present, future," Solar energy materials and solar cells, vol. 74, pp. 1-11, 2002

[21] S. Alshkeili and M. Emziane, "Design of Si/Ge dual junction solar cell devices," Energy Procedia, vol. 42, pp. 698-707, 2013 